\title{
Review Article: How Far is Global?
}

\author{
Roy Flechner*
}

Catherine Holmes and Naomi Standen (eds.), The Global Middle Ages, Past and Present 238, Supplement 13 (Oxford, 2018) xxii+441pp. +7 Maps ISSN 0031-2746

The global turn in medieval history continues to swell. A recent spate of single- and multiauthored volumes is now bolstered by the appearance of three new journals, whose issues - in whole or in part - are committed to a global perspective: The Medieval Globe (founded 2014), Medieval Worlds (founded 2015), and its near-namesake Journal of Medieval Worlds (founded 2019). This build-up of publications is a welcome expression of self-validation, and the journals in particular betoken a sense of confidence in anticipating the field's longevity. Notwithstanding these auspicious omens, the fledgling field of the Global Middle Ages faces lingering challenges as it continues to forge its identity. One such challenge is the internationalisation of the field itself.

In contradistinction to the subject's unbounded geographical reach, few publications in the field evince systematic collaboration with colleagues in universities outside North America or the west of Europe. The volume under review here, The Global Middle Ages, is no exception. It developed from the activities of the research network "Defining the Global Middle Ages «, centred at the Universities of Oxford, Birmingham, and Newcastle. The original group consisted of thirty-three historians and archaeologists specialising in Eurasia, Africa, and the Americas (Australia and the South Pacific islands are excluded). Of the sixteen who contributed to the eventual volume, all but one are British academics, nine of whom are based in Oxford. The one exception, Hilde De Weerdt, is from Leiden. While the choice to collaborate almost exclusively within British academe may not be as intellectually adventurous as one would expect from a group that espouses "the indispensability of collaborative methods, most notably in the field of global history " (p. 23), it reflects a regional exclusivity that is by no means peculiar to this research group, nor is it suggestive of a uniquely western scholarly bias. The rise of global history in East Asia has had to contend with similar parochial tendencies. Nevertheless, in surveying global history initiatives from Japan, Korea, China, and Taiwan, Edward Wang observes an increasing readiness among modernists to widen participation, which is in keeping with a similar trend driven by modernists elsewhere in the world. Medievalists have yet to catch up.

Such ironies aside, the authors of the Global Middle Ages make the most of the collaborative momentum to set a new course in "thinking globally" about the period. Like other global projects from recent years, The Global Middle Ages brings together a strong roster of experts - only a minority of whom self-identify as global historians - to try their hand at addressing global themes or at rehearsing their specialisms in a global context. Most of

* Correspondence details: Roy Flechner, School of History, University College Dublin, Belfield, Dublin 4, Ireland; email: roy.flechner@ucd.ie. The author thanks Helle Vogt and Charles West for their comments on a draft script. 
the contributions were written jointly by two or more authors, and the sum total proves to be a dynamic volume that harmonises a diverse range of methods and interpretations. The contributors deliberately eschew conventional themes in global history, preferring instead more open-ended categories. This is not to say that international politics, the vicissitudes of empires, trade, and intellectual connections are absent, but they are not the principal categories of inquiry. Instead we find "globalizing cosmologies«, "networks«, »structural mobilities«, »trust in long-distance relationships«, »economic imaginaries", »settlement, landscape and narrative«, and "politics, c. 1000-1500: mediation and communication«. A concluding chapter which expresses a degree of dissent with preceding arguments is a welcome expression of self-reflection. Especially stimulating are the volume's professed experimental tenor and its relentless pursuit of sharper theoretical and methodological resolution in probing the "global«. Accordingly, the present review will concentrate more on the strands of thinking that give weave and texture to the overall approach than on the merit of individual contributions.

The principal method that the authors follow is what they call the "combinative" method, which - as Catherine Holmes and Naomi Standen explain in the introduction - »combines rather than formally compares case studies, and which sets the local and the global in dynamic conversation" (p. 3). The combinative method is presented as the antithesis to grand narratives and their propensity to blunt diversity of all kinds. Although the editors do not rule out the emergence of a grand narrative at a more advanced stage of research, they believe that what works best for the early explorative phases is "a bottom-up methodology that does not simply accommodate but takes advantage of difference« (p. 3). The combinative method allows the authors to optimise their individual strengths in the collaboration, to the extent that "combinative" and "collaborative" become interchangeable. At the same time the combinative method releases the authors - as a collective - from the pressure to submit to an agreed overall narrative. Nevertheless, hints of what a grand narrative may one day look like can be found in the editors' discussion of "the Global Middle Ages as a working hypothesis « (pp. 36-41), which admits a number of grand-narrative-like abstractions, principally Robert I. Moore's "Great Diversification « and "Great Intensification" throughout Eurasia (pp. 36-37). The "Great Diversification« thesis, ultimately informed by Kenneth Pomeranz's influential Great Divergence (2000), hinges particularly on the first division in Pomeranz's book: "A World of Surprising Resemblances«. Moore, a member of the network's original cadre, developed the "Great Diversification" paradigm to replace his own theory of a "Great Divergence" in Eurasia in the twelfth century, a theory that contrasted Latin Europe with China by portraying the former as following a trajectory towards more institutionalisation and less kin-based local power. That view was dislodged by his more nuanced re-reading of conditions in South East Asia, a re-reading that no longer gave pride of place to formal institutions.

As for "Great Intensification«, the volume's editors join Moore in subscribing to a "working model« of the Global Middle Ages "characterized by increased economic activity, urbanization, social restructuring, multi-centred politics and new frameworks of ideas" (p. 36). The extent to which "Intensification" or "Diversification ", or other labels that purport to describe long-term shifts lend themselves to empirical validation is casually questioned on the following page. Labels of these kinds also impinge on periodisation, prompting the question whether any attempt to distinguish one period from another by comparing rates of »increase «, "diversification", and so on amounts to a hubris of quantifying the unquantifiable with predictably arbitrary outcomes. A case in point is Moore's own observation (in 
»The first Great Divergence?«) that in 2009, the same year in which he published his »Medieval Europe in world history «, where he argued for a twelfth-century »Great Divergence« in Eurasia, Walter Scheidel, in his edited volume Rome and China, independently dated the beginning of his "Great Divergence« to the sixth century.

Beyond the Introduction the volume remains in occasional dialogue with the notion of a "Great Divergence« but neither "Great Divergence« nor any other global paradigm is actively endorsed. With the exception of the penultimate chapter, the volume has also emancipated itself from "World Systems " theory, with its emphasis on a competition to dominate interconnected global commercial circuits, and also from perspectives that circumscribe the role of human agency by privileging pandemics, the climate, or the environment more generally.

The first of the ten chapters (but technically "articles", because this is a journal supplement) is the late Mark Whittow's "Sources of knowledge; cultures of recording ". It discusses forms of available written and material evidence, but also lost evidence, and the deliberate destruction of evidence. Examples are drawn from sixth-century Ethiopia, seventh-century Egypt, from the knotted strings (khipus) of the Inca, the mixed logographic/syllabic script of the Maya on the eve of the Spanish landing, the adaptation of the Nahuatl script of the Aztecs of Mexico to a version of the Latin alphabet, and the bureaucratic control of literacy in China, where archives were cleared periodically since the dawn of the Tang dynasty. Whittow concluded that what is typical for every place in this period »is its very peculiarity - the characteristic of idiosyncrasy that applies to everywhere that has preserved evidence for the Middle Ages, anywhere in the world « (p. 87). Despite claiming earlier in the chapter that the conclusion "may seem obvious" (p. 48), it gains significance when read in connection with observations made elsewhere in the volume, and I shall return to it.

In the spirit of challenging paradigms, the following chapter puts forward bold propositions regarding connectivity or the lack thereof and inter-cultural awareness which go a certain way towards redefining "global« as a category for historical research. "Globalizing Cosmologies", by Caroline Dodds Pennock and Amanda Power, articulates some of the volume's core approaches to historicising the "global« and to the problem of periodisation. As explained in the Introduction, "their approach to these issues of definition has shaped the thinking of all members of our original project network and is reflected throughout this book" (p. 3). Overall, however, the network seems to have preferred to defer a more robust consideration of periodisation indefinitely.

The two authors utilise examples from Aztec Mexico and from the interaction between Latin church leaders and Mongol leaders in the thirteenth century to argue that a "globalising cosmology « is not premised on the interactions between cultures, not even on the attempt of one culture to imagine others beyond it, but on the capacity of a culture to develop its own coherent world (and other-world) views. This capacity can be detected in attempts to validate worldviews for the benefit of constituent members or to impart these worldviews to others. The chapter makes this point a number of times with different emphases, for example on p. 113 we read that "the value of the rglobalizing cosmology lies not in the way a society imagined its connections, its trade routes, but in its capacity to show the richness, variety and dynamism possible in sglobal thinking ". The contrast here is with more conventional approaches to global history which prioritise connectivity and the accumulation of knowledge about other cultures. A recent example is the fifth volume of the Cambridge World History series, Expanding Webs of Exchange and Conflict: 500 CE-150o CE (2015), edited by Benja$\min$ Z. Kedar and Merry E. Wiesner-Hanks. The title aptly captures the appeal to connectivity, from sporadic contacts between cultures to more intentional forms of contact, which include 
war, conquest, and trade, but also the spread of religions and the transmission of ideas, which can take place either intentionally or unintentionally. Such connections, pace Kedar and Wiesner-Hanks, ought to be the primary concern of the global historian of the period that they call the Middle Millennium. Connectivity and a desire to learn about cultures other than one's own are the forces that shaped what Kedar and Wiesner-Hanks call »contemporary views of the known world «, which they observe in "world maps « (the earliest are from tenth-century Balkh) and in the few written histories from this period that transcend the narratives of specific "nations « or empires. By comparison, Dodds Pennock and Power's historicising reflects a decidedly post-modern interpretation which identifies power as a factor in contemporary conceptualisations of the "global«. They argue that "globalizing cosmologies were thus frequently hegemonic, and recorded normatively by almost exclusively male elites, who could draw on them in an attempt to position their office and actions more securely" (p. 112).

In contesting the idea that a globalising cosmology is necessarily contingent upon a desire to explore outside one's own culture, Dodds Pennock and Power define it instead as a tendency to maximise the integration of all the manifestations of a culture's visible and invisible features. For examples they turn to what they call "Latin Christian thinking " and to the Aztecs. In relation to the Aztecs they write: "This was a truly rglobal cosmos, a view which saw every part of the world, physical, spiritual and natural, individual and communal, as interdependent « (p. 105). This was a self-contained endeavour independent of any form of engagement with another culture. The authors' choice of the word "global« to capture this "pre-modern totalizing construct in which social, religious and cosmological orders were integrally linked« (p. 105) is among the volume's most radical propositions.

The next chapter, "Networks", takes a sharp turn in the direction of a more familiar "global « narrative, holding that "a prime concern of global history is, after all, with the connections between the groupings and communities living continents, if not oceans, apart « (p. 116). Concentrating especially - but not only - on networks along the Silk Roads, Jonathan Shepard observes three registers of pre-modern global networks: things, persons, and ideas. He excludes the Latin church in the Central Middle Ages from counting as a network (p. 121) because by having a "centre-point or command chain« it defies the principle of "voluntary participation", which is the chief criterion by which he defines a network (p. 116). This seems to set a rather high bar of exclusivity on the definition, which places on the author an onus of justifying how other structured connections that he examines - especially commercial connections - are neither hierarchical nor centralised. But he doesn't do this. Instead, if I understand him correctly, he exploits contingencies insinuated into the preamble to his definition to allow it to encompass even Franciscans and Dominicans, who are said to have operated through networks in establishing episcopal sees, as overland routes along the Silk Roads became more secure under Mongol control (p. 148). Shepard pushes the boundaries of his definition of "network" further by admitting groupings of traders characterised by a dynamic that combined voluntary participation and hierarchical control, which facilitated coordination but was also responsible for instances of coercion in interactions with local powers. The workings of Portuguese commercial networks are a case in point (pp. 151-155), and Europeanists would probably cite the Hanseatic League, which is outside the scope of his chapter, as a similar manifestation of this dynamic. We see in this chapter restrictive definitions being offered but not adhered to rigidly. Consequently, what may have appeared initially as inconsistency is transformed into an opportunity to challenge assumptions and to proffer new insights, which in this particular case include the observation that modern writers' preoccupation with the overland Silk Roads may have unduly eclipsed the importance of the maritime Silk Roads (p. 144). 
In "Structural Mobilities", a dizzyingly rich chapter, Naomi Standen and Monica White set out to explore the heuristic of comparing mobilities of settled and nomadic populations. Structural mobilities are identified as a means to various ends. These range from plain survival, to facilitating communication and commerce, to political expediency, to diplomatic missions, to military manoeuvres. The need for mobility was ubiquitous and no one could have done without it. Mobility between the settled centres of the Sogdian (inhabiting parts of modern-day Uzbekistan and Tajikistan) enabled trade, and five fourth-century letters testify not only to the utility of mobility between such centres, but also to the consequences of disrupted mobility. The failure of kin networks to respond to individuals in their hour of need highlights the frustration of having to turn instead to official networks, which could prove unreliable in times of crisis. In one letter stranded Sogdian are said to have died of starvation in the city of Luoyang. In another letter a servant runs away, placing an isolated mother and daughter in jeopardy: "his successful movement denied the women theirs" (p. 170). For the Byzantines the most large-scale movement was that of the army, while Mongol military strategy could rely on such precise knowledge of vast landscapes that they were able to strategise for campaigns thousands of kilometres away. This knowledge also meant they could plan ahead and did not have to rely on messengers as much as their adversaries from the ill-fated Jin dynasty, which was defeated in 1234. For the Jin, as well as for the Song and for many a Eurasian dynasty, mobility was essential for governing, but also for displaying power and delineating boundaries of political legitimation. A government official would gain status when seen to be travelling regularly for discharging his duties or for attending the court. But, having fallen out of imperial favour, visits to the court would cease, causing him to lose face. Mongols would inflict similar humiliations by banning someone from joining a hunt. The authors stress that »distance was not a factor here: mobility across just a few hundred metres had the same structural importance as travelling from the ends of the empire (p. 174). These hunting nobles join the imperial officials, the soldiers, and the messengers described in the chapter's detailed case studies to tease out the conclusion that "mobility (and its difficulties) was, in fact, a structural element of medieval Eurasian societies, particularly those characterized as sedentary“ (p. 187).

Trust is the theme of the following chapter, by Ian Forrest and Anne Haour. The authors concentrate on trust in long-distance relationships, which, as they see it, is one of three main strands of global history, the other two being comparative history and the history of common experiences. Trust is the abstract and often unspoken quality that enabled - or in its absence hindered - forms of interaction explored in the book's other chapters, be it the dynamics of networks, the viability of trade, or political connections. It is also in these contexts that one can observe acts of trust being performed spontaneously or ritualistically. Forrest and Haour focus on trade, using examples from west Africa, north Africa, the eastern Mediterranean, and England. Spaces associated with trade, like markets or merchant quarters, are also arenas in which trust may be established, tested, and displayed through performative acts. The authors find merit in Niklas Luhmann's notion of a distinction between trust in persons and trust in institutions but they reject a clear dichotomy. The belief that a common culture promotes trust (e.g. in Paul Lovejoy's »diaspora model«) is moderated by questioning the harmony of merchant communities (Francesca Trivellato). Common culture may be a precondition for trust among merchants, or the mercantile lifestyle itself may constitute a form of common culture. The authors highlight the importance and difficulties of relating historical examples to theoretical models, bemoaning some theoretical studies that show a "tendency to generalize and simplify, even where some attempt at historical contextualization is made« (p. 192). 
Trust is also an important plank of Simon Yarrow's chapter, "Economic Imaginaries", whose opening paragraph stresses its centrality to determining value by asking "what constitutes value and who says so«? (p. 214). The chapter displays a certain predilection for jargon also manifested in the title, which Yarrow explains thus: "I borrow the germane phrase reconomic imaginary from Tamara Chin's recent examination of classical Confucian writings and material cultures of Han China (206 BCE-220 CE). I gloss the term here as a historically situated complex of literary and material discourses productive of meta-narrative themes of theodicy, providence, governance and identity, rendering them legible, reproducible and contestable in concrete terms « (p. 218). This broad definition, prompted by a book about Han China, aims to draw the observer away from themes that dominate economic debates in the western historiographical tradition, which the chapter proceeds to critique. One such critique is the observation that the influences of secular constitutionalism and liberal historicism "on historiography and the social sciences have made for a peculiarly narrow modern western view of the historical relationship between governance and wealth, the extent of whose colonizing effects on both the medieval and the non-European past have only relatively recently become apparent to scholars" (p. 215). The critique extends to questions of periodisation and to interpretations of the origins and dynamics of economic forces (Adam Smith, Karl Marx, and Max Weber, are among the more familiar names), stressing the dependence of these interpretations on Western-centric paradigms of various kinds, like the uniqueness of European capitalism, the implicit or overt acceptance of (Western) Christian values, or the reaction against such values. Western intellectual traditions gloss over important milestones in non-Christian medieval economic thinking, especially ones from the Islamicate world, the rise of which is said to constitute "the most singular and consequential event of medieval globality« (p. 226). That world brought forth the likes of al-Ghazali, Ibn Taymiyya, and Ibn Khaldun, whose shrewd understanding of market forces is held up as equal to Smith's. It is not only the richly diverse roots of economic theory that come into view when a global perspective is applied, but also similar economic practices across cultures. A striking example are the contemporaneous eighth-century campaigns against "tax-evading " monasteries in both Northumbria and the Buddhist Kingdom of Khotan, in what is now western China (p. 224).

Distant similarities are a feature also of the chapter "Settlement, Landscape and Narrative: What Really Happened in History", by Conrad Leyser, Standen, and Stephanie Wynne-Jones. This is a somewhat enigmatic title that carefully tiptoes around concepts which the chapter ultimately seeks to deconstruct. What the title tries, but at the same time tries not to say, is that the chapter is about towns as defined by their function, but also about urbanisation as a construct, and about the inadequacy of the model proposed by Gordon Childe in his What Happened in History (1942). This is a model that the authors hold up as an »ideal type « (p. 234) for hypotheses that teleologically frame "history as a journey towards complex, urban civilization « (p. 233). Towns are not always towns in their familiar European or Eastern Eurasian manifestations, and historians must shed their most basic preconceptions in order to be able to engage with urbanism elsewhere in the world. Even the notion of a place of habitation with fixed coordinates in the landscape can be a false proposition. What the authors call "pop-up « urbanism (e.g. p. 240) was common in Africa: »Great Zimbabwe and the Zimbabwe tradition thus seem to represent fixed points in a mobile landscape, with urban life coming together perhaps only on a seasonal basis" (p. 238). These »pop-up " places are argued to bear comparison with early medieval European emporia. Even the political capital of the empire of Mali (thirteenth to fifteenth century) was not a single place: "authority and permanence were not functionally linked« (p. 237). A global approach to both archaeological evidence and 
narrativising is shown here to help historians to draw sharper distinctions. These are exciting observations to which one may add the pre-Viking »urban« landscape of Ireland, which was no less imagined than real. There, as in other places, traditions of storytelling constructed narratives of urban development which, as the authors say, create a misleading but powerful impression »of permanence and embeddedness in an agricultural hinterland « (p. 260).

As a consequence of the volume's choice to concentrate on phenomena defined by human agency and experience, every chapter faces the challenge of balancing, on the one hand, contingencies that are specific to persons or to singular interactions between persons, and on the other hand, broad analytical abstractions that enable a "combinative" conversation across borders, cultures, continents, and other dividers. The risk of letting abstractions obscure or trivialise what is unique and distinctive is amplified in the area of politics, where the force of personalities is a dominant, if often overstated, catalyst of conventional historical narrative. It would be strange, for example, to omit Charlemagne from a history of eighth- and ninth-century Europe but at the same time it would be wrong to make him into a Carlyleesque "great man" ("I was taught at my mother's knee to bridle at those words", writes Janet Nelson, his most recent biographer). And it would be stranger still for a volume concerned with man-made phenomena to omit politics from an investigation of the Global Middle Ages.

As its title suggests, the chapter "Politics, c. 1000-1500: Mediation and Communication" explores the role of mediation and communication in politics. The authors, Hilde De Weerdt, Catherine Holmes, and John Watts, are interested in general dynamics (though not so general as to become platitudes) deduced from three case studies involving Song China, Byzantium, and France between the eleventh and fifteenth centuries. Processes rather than turning points are what the authors look out for. These can be processes of vertical mediation between formal institutional power and informal expressions of power or between centres and localities. But there are also horizontal processes of mediation, connecting localities to one another. Communication is more loosely defined and the authors deliberate whether "Communicators were a kind of mediator, and perhaps all mediators were communicators « (p. 263). Chinese students training to become civil servants are shown to have been able to wield significant power as mediators representing the interests of local communities, of their own peer-group, and of their institutions. On one occasion at least, Chinese students successfully pressurised Emperor Gaozong to dismiss officials who were deemed responsible for an invasion by a foreign power, the Jurchens. Yet when a student leader, Chen Dong (1086-1127), was deemed to go too far, he was executed but posthumously rehabilitated at the emperor's orders and inserted into the official records of the dynasty's history. Protests by Chinese students were not uncommon, and the authors note that students in both 1919 and 1989 "applied the same repertoire of techniques of political communication (such as posters, handbills and petitions to the central government) that had been in use for centuries« (p. 276).

The second case study, of France during the civil war of 1405-1419, develops the concept of a political imaginaire, which will be central to the chapter's conclusions. Controlled communication reconfigures ideas of rulership, of legitimacy, and of loyalty. Following the murder in 1407 of Duke Louis of Orléans, who seized the regency, two political factions emerged, the "Armagnacs", comprising the surviving followers of Orléans, and the "Burgundians", who eventually sided with the English invaders. Louis's rival John (himself murdered in 1419) deployed sophisticated strategies of brokerage and communication, both formal and informal, to project more ideological and structural coherence in a fragmented polity. His rivals were attempting the same, casting themselves as the party of order. Two power structures can be observed: the first was the damaged royal structure, nominally headed by an inca- 
pacitated king and weakened by the invaders' presence, but still in possession of a royal administration and a system of taxation. The second comprised semi-independent aristocratic, ecclesiastical, and local powers. Within either structure there were different influential players to be wooed for support and different interests to try to appease by deploying diverse tactics. Throughout one observes how "the communication strategies of leading mediators reinforced the imaginaire of the kingdom « (p. 282).

The final case study is of the Palaiologan dynasty in the late Byzantine period, characterised by increasing fragmentation and continually challenged by regional rivals. The dynasty nevertheless exercised communication with the different localities within which it sought to legitimise its rule. Records of the mediators who facilitated this communication show, for example, how negotiations could lead to the peaceful surrender of various cities under Bulgarian control. But it is easier to identify who had surrendered than to whom they had surrendered: was it a coherent political entity or merely the semblance of one? When certainties were absent, the answer was determined by what could be negotiated, and this was where communication could make a big difference to reinforcing the imaginaire.

In reflecting on the case studies the authors highlight the role of mediation and communication in maintaining the imaginaire, which was defined at the beginning of the chapter as a framework in which "an entire political society was continuously created, critiqued and reshaped« (p. 263). The three political societies they examine are argued to reflect gaps of varying degrees between imagined structures of power and the realities of power. Reality can fall short of the ideal or, alternatively, it can catch up with political spin. There are implications for political history in regional historiographies elsewhere in the medieval period, and the authors tease some of these out with an appended cautionary note that »it is important not to overdraw parallels« (p. 295).

In the penultimate chapter the late Glen Dudbridge explored global movements and exchanges that were driven not by economic motives (at least not primarily by them) but by a desire to exchange books and knowledge, which cemented learned contacts between India, China, Korea, and Japan, beginning in the seventh century. By the ninth century this »Book Road" (p. 302), a term coined by Wang Yong, had a conspicuous effect on Japanese culture. These books, we are told, "were instrumental for establishing the statutory law system, for the emergence of Tendai and esoteric Buddhist schools in Japan, the transmission of Tang poetry collections and poetics, devotional art, architecture, court music and more« (p. 302). These were, in effect, "the Chinese books and ideas that would serve the state-builders of medieval east Asia " (p. 298). This chapter, titled "Reworking the World System Paradigm «, is framed as a response to the once-influential Before European Hegemony: The World System A.D. 1250-1350 by Janet Abu-Lughod, originally published in 1989. There she posited eight intersecting zones, each defined primarily through links of commerce and production. It is such links - but also intellectual links - over a large geographical and chronological span and over highly complex interlocking networks that often emerged organically, for which Dudbridge seeks a new metaphor, »adequate for representing those processes of world history « (p. 298). Buddhist monks, some of whom we know by name and even from their own accounts, were regular travellers of the intellectual routes and witnesses to the geographical span of these networks. The travels of a Korean Buddhist monk, Hye-ch'o (d. c. 787), by land and sea through India and China (he was not the first to achieve this), scopes a global vision of paths, of transforming cultures, of changing religions, and of shifting political dominions, especially in "frontier « zones. In visiting one of these zones, on the easternmost limits of the Abbasid caliphate, he reported changes-in-progress as political conquest was underway, but he witnessed only limited re- 
ligious change as Buddhism and Zoroastrianism continued to be widely practised alongside Islam. How can the historian capture all this in metaphorical language? »The challenge for a world system draughtsman is to find some metaphor that can do effective justice to all that non-linear activity« (p. 314). What Dudbridge eventually opted for is a metaphor borrowed from a model used by physiologists, known as the »reductionist causal chain « model (associated with Denis Noble), which talks about complex organic systems in which causal links operate in many directions, but analysis can begin at any point in this system, because all points are ultimately causally connected. Unlike the "combinative « method, this is a metaphor that aims to account for what global history is, rather than for how it should be practised. The two are able to complement each other in a simple means-to-ends relationship.

Alan Strathern's concluding chapter is a reflection on both the network's activities and the volume's earlier chapters from the vantage point of a historian of the Early Modern period. His objective wis to connect the emerging field of the Global Middle Ages with the somewhat more established field of Global Early Modernity, and to flesh out some of the conceptual problems and points of tension that arise when we consider them together " (p. 317). It is from the perspective of early modernity that he offers a critique not only of the Global Middle Ages as a fledgling field, but also of certain approaches and attitudes adopted by the network itself. He begins by identifying two aspects in which the network's discussions were conducted in a disconnect with Global Early Modernity and with early modernity more broadly. The first was the proclivity to address modernity with little reference to early modernity and the second was the suspicion towards notions of globalisation, modernisation, and imperialism, because they were identified with European agency, an agency that global medievalists are primed to play down (a recent example is Peter Frankopan's contribution to the inaugural issue of Journal of Medieval Worlds). But this identification may be assuaged simply by stressing the agency of non-Europeans, which is how, according to Starthern, Global Early Modernity "decolonized« these phenomena. He also believes that the network should devote more attention to questions of periodisation. One should ideally strive to define the Global Middle Ages for what it was rather than for what it was not, although the latter approach has a proud legacy, rehearsed recently by Diego Olstein, who borrowed Shmuel N. Eisenstadt's notion of "Proto-globalisation" to define a "Middle Millennium « that harked back to structural features of the Axial Age while sowing the seeds of globalisation for modernity to reap. The alternative to periodising by positive or negative criteria is to leave the Global Middle Ages in a limbo, "content-less so that it acts as a neutral container. This was the route initially taken by the Global Middle Ages project, which allowed contributors to proceed without any analytical preconceptions« (p. 331).

The chapter then explores two analytical approaches to a Global Middle Ages: "connectivity" and "comparability" (puzzlingly, the "combinative« method is not mentioned at all). The first approach surfaces occasionally in the preceding chapters, especially Shepard's, but it is not one which the network endorses, and Strathern himself cautions that "global history ought not to be conflated with connectivity« (p. 344), as it would submit the Global Middle Ages to the grand narrative of globalisation (p. 320). Strathern agrees with Moore that processes of divergence rather than connectedness are just as evident, if not more evident in the period 600-1000, such that by the end of this period Eurasian civilizations were more different from one another than they had ever been. Connectedness and divergence are therefore also criteria for periodisation, and the latter deserves just as much attention as the former because "certain kinds of isolation are no less exciting" (pp. 334-335) and there is virtue even in acknowledging incommensurability (p. 336). 
The second approach to the Global Middle Ages, comparability, does not assume connectivity, but does not conflict with it either. For early modernists, "the whole >Great Divergencer debate has enhanced the status of comparative history as a means of addressing important questions about causation « (p. 324). But to make the most of comparative history it is necessary to identify significant categories for comparison, and these may be found across societies at different times, corresponding to their different paces of development. A case in point is Chris Wickham's recent comparison of economic patterns between northern Italy and the Jiangnan region of China in the central Middle Ages: Wickham is obliged to occasionally expand the time frame in order to fully capture the patterns that he is after. In making global comparisons contemporaneity may have to be sacrificed - we may occasionally even have to cross over into early modernity - and so we find ourselves again grappling with the appropriateness of boundaries set by conventional periodisation and with the need for a clearer demarcation of the "Middle Ages « as a distinct period in a global history.

The tension between connectivity and comparability turns the spotlight onto the ostensibly banal question of how ought a global historian choose what places to study in the first place. The answer is simple enough if connectivity is admitted as a defining principle: it will then be a matter of following the connections. But these will only take you so far. In the volume under review the contributors chose to look beyond the places that ordinary connections would allow and instead juxtaposed Aztecs and Mongols, England and west Africa, Song China and France, and so on. Taking these distant places together without suppressing regional peculiarities triggered valid insights about the relationship that humans around the globe had with trust, mobility, or with formal and informal political communication. As the editors had hoped, the combinative method proved to be successful in setting "the local and the global in dynamic conversation « (p. 3), a success that owes a lot to a fruitful collaboration between historians, who brought their regional specialisms to bear on big questions. If the conversation is to continue beyond the activities of the original network then it will be good to see it enriched by reaching out to historians outside Europe and North America. This will be a conversation in which curiosity about medieval events and personalities will also nurture curiosity about different - sometimes vastly different - historiographical legacies. The "combinative" method seems apt for accommodating both.

No study, however sophisticated and however inclusive in terms of its participants, can be expected to take in the entire globe at once. In the volume under review the places examined corresponded to the contributors' range of expertise. And this is fine: admitting places by an arbitrary selection criterion is as good an antidote as any against teleological thinking. But is there such a thing as a place too near to be global or a place too far to be reasonable? Put more provocatively: How far is global? Reading between the lines of the Global Middle Ages one finds different answers to this. I note three. The first says that it is possible to examine a single society and still be global: of the societies discussed in "Globalizing Cosmologies ", the Aztecs are accepted as having a global cosmology even though they cannot be shown to have even contemplated a physical world beyond the geography that they knew. A »truly rglobal cosmos", we are told, is a single society's self-contained "view which saw every part of the world, physical, spiritual and natural, individual and communal, as interdependent « (p. 105). The second - in »Reworking the World System Paradigm« - draws us into a geographical ambit that is more clearly defined by cultural connections, even though the peoples inhabiting it and its fringes can be quite different. And the third - in "Settlement, Landscape and Narrative - juxtaposes distant places but is not premised on connections. These are clearly three different perspectives, but there seems to be a thread that joins them all. We glimpse 
this thread in Whittow's observation that what is typical for every place in the Global Middle Ages is the quality of peculiarity and idiosyncrasy (p. 87), in Strathern's praise for incommensurability (p. 336), and finally, in recalling the definition of the combinative approach as "a bottom-up methodology that does not simply accommodate but takes advantage of difference« (p. 3). What this thread amounts to is an acknowledgement that thinking globally is a way of »creating space for difference«. This means that the global historian does not simply assume difference and then revels at identifying the occasional similarity (to do this amounts to nothing more than debunking one's own prejudices) but the other way around.

For the globalist distance is a convenient proxy for difference, but as the Global Middle Ages shows, when distance itself is not fetishised then "global thinking " can arguably be observed even in the cosmology of a single culture or in structured mobilities across short distances (pace Standen and White). The reader is invited to share in the excitement of identifying difference in human experience and of giving meaning to it, especially in a period in which differences were more prevalent and more conspicuous than similarities. This quality of idiosyncrasy - rightly argued by Whittow to apply to every medieval place and to be a defining feature of the Global Middle Ages - must also be the point of departure for periodising the Global Middle Ages, a matter which, if left unresolved, will continue to cut an awkward figure as the elephant in the room.

That the volume's relentless questioning stops short of questioning periodisation would be understandable should the expected outcome be a choice between two equally undesirable options: either an endorsement of a trivial packaging of time or a questioning of the field's raison d'être. The first is not really an option for a volume that (rightly) refuses to be prescriptive. But it seems to me that the second option is not as insidious as it may at first appear: the ultimate proof that the Global Middle Ages is already an established field may be the fact that we can doubt it but continue practising it nevertheless; which is the case with most historical periods. 


\section{References}

Abu-Lughod, Janet, Before European Hegemony: The World System A.D. 1250-1350 (New York, 1989).

Childe, Gordon, What Happened in History (Harmondsworth, 1942).

Chin, Tamara, Savage Exchange: Han Imperialism, Chinese Literary Style, and the Economic Imagination (Cambridge, MA, 2014).

Frankopan, Peter, Why we need to think about the global Middle Ages, Journal of Medieval Worlds 1 (2019) 5-10.

Kedar, Benjamin Z. and Merry E. Wiesner-Hanks (eds.), Expanding Webs of Exchange and Conflict: 500 CE-150o CE, Cambridge World History 5 (Cambridge, 2015).

Lovejoy, Paul, Caravans of Kola: The Hausa Kola Trade 1700-190o (Zaria, 1980).

Lovejoy, Paul, The role of the Wangara in the economic transformation of the central Sudan in the 15th and 16th centuries, Journal of African History 19 (1978) 173-193.

Luhmann, Niklas, Trust and Power (Chichester, 1979).

Moore, Robert I., The First European Revolution c. 970-1215 (London, 2000).

Moore, Robert I., The first Great Divergence?, Medieval Worlds 1 (2015) 16-24.

Moore, Robert I., Medieval Europe in world history, in: Carol Lansing and Edward D. English (eds.), A Companion to the Medieval World (Oxford, 2009) 561-580.

Nelson, Janet, King and Emperor: A New Life of Charlemagne (London, 2019).

Noble, Denis, The Music of Life: Biology Beyond Genes (Oxford, 2006).

Olstein, Diego, "Proto-globalization« and "Proto-glocalizations« in the Middle Millennium, in: Benjamin Z. Kedar and Merry E. Wiesner-Hanks (eds.), Expanding Webs of Exchange and Conflict: 500 CE-150o CE, Cambridge World History 5 (Cambridge, 2015) 665-684.

Pomeranz, Kenneth, The Great Divergence: China, Europe, and the Making of the Modern World Economy (Princeton, 2000).

Scheidel, Walter (ed.), Rome and China: Comparative Perspectives on Ancient World Empires (Oxford, 2009).

Trivellato, Francesca, The Familiarity of Strangers: The Sephardic Diaspora, Livorno and Cross-Cultural Trade in the Early Modern Period (New Haven, 2009).

Wang, Edward Q., Re-presenting Asia on the global stage: The rise of global history in East Asia, in: Sven Beckert and Dominic Sachsenmaier (eds.), Global History, Globally: Research and Practice around the World (London, 2018) 45-66.

Wang Yong, ZhongRi 'shuji zhi lu' yanjiu [A Study of the "Book Road« between China and Japan] (Beijing, 2003).

Wickham, Chris, Jiangnan style: Doing global economic history in the medieval period, in: John Arnold, Matthew Hilton and Jan Rüger (eds.), History after Hobsbawm (Oxford, 2017) 121-139.

\section{Journals}

Journal of Medieval Worlds (University of California Press; founded 2019)

The Medieval Globe (Arc Humanities Press; founded 2014)

Medieval Worlds (Institute for Medieval Research of the Austrian Academy of Sciences; founded 2015) 